\title{
Mechanical and dynamic mechanical behaviour of novel glass-natural fibre intra-ply woven polyester composites
}

\author{
M RAJESH $^{1}$ and JEYARAJ PITCHAIMANI ${ }^{2, *}$ (B) \\ ${ }^{1}$ School of Mechanical Engineering, VIT University, Vellore 632 014, India \\ ${ }^{2}$ Department of Mechanical Engineering, National Institute of Technology Karnataka, \\ Surathkal, Mangalore 575 025, India \\ e-mail: rajesh261288@gmail.com; pjeyaemkm@gmail.com
}

MS received 24 February 2016; revised 19 September 2016; accepted 19 January 2017

\begin{abstract}
A novel intra-ply woven fabric polyester composite with glass fibre yarns in one direction and natural fibre yarns in another direction of basket-type woven fabric has been investigated for mechanical and dynamic mechanical characteristics. Individual glass fibre woven fabric, natural fibres woven fabric and intraply natural fibres woven fabric composites are also investigated for the comparison purpose. Results reveal that the intra-ply woven fabric hybridization enhances impact and damping properties of the composite significantly than the tensile and flexural properties. Intra-ply woven fabrics with glass fibre yarns in warp direction and jute fibre yarns in weft direction (WGWJ) exhibit better impact properties compared with woven fabric with other combinations. Dynamic mechanical analysis results reveal that intra-ply woven fabric composite with glass fibre yarns in warp direction and jute and banana fibre yarns in weft direction (WGWJAB) gives higher damping characteristics due to the multi-level interaction between fibre-fibre and fibre-matrix interactions.
\end{abstract}

Keywords. Intra-ply hybrid; natural fibre; mechanical properties; dynamic mechanical analysis; vibration; scanning electron microscopy.

\section{Introduction}

In the last few decades, usage of polymer in mechanical, automobile, civil, aerospace and structural applications tremendously increased due to their easy availability, good mechanical properties and low cost compared with conventional material $[1,2]$. The main advantage of polymers is their easy preparation, production and reduced cost in comparison with conventional materials. In order to improve the use of polymer in several polymer applications, researchers are suggesting the addition of filler or fibre in the polymer matrix to enhance the performance of the polymer material [3]. Many researchers added man-made fibres (glass, carbon, kevlar and boron) as a reinforcement in polymer to improve the mechanical behaviour. Fu et al [4] analysed the tensile properties of short glass and carbon fibre reinforced composite regarding various factors and found that volume and length of fibre influence tensile properties of the composites. Lassila et al [5] studied the effect of volume percentage of glass fibre in a polymer and found that $45 \mathrm{vol} \%$ gives better flexural strength.

Nowadays natural fibres are employed to fabricate the fibre-reinforced composites for mechanical, civil and aerospace structure in low and medium load applications. This is due to their lower weight, better thermal and

*For correspondence insulation properties, low energy consumption during processing, good acoustic behaviour and easy availability of resources [6,7]. Natural fibres are more eco-friendly than man-made fibre such as glass, carbon and kevlar fibres [8]. Corbire-Nicollier et al [9] proved that in polymer composites the man-made fibres are successfully replaced by natural fibre with equivalent property. Several researchers analysed the effect of hybridization of two different natural fibres on various properties of polymer composites. Venkateshwaran et al [10] studied the mechanical properties of banana-sisal-epoxy hybrid composite. They found that hybrid composite with $50 \mathrm{wt} \%$ of sisal fibre combination gives better mechanical properties than other combinations. Sastra et al [11] investigated the tensile behaviour of arenga pinnata fibre-epoxy composites and found that the woven fibre composites give better properties than long random, chopped random composites. Okubo et al [12] studied the tensile properties of bamboopolypropylene composite and found that bamboo fibre bundle composite improved the tensile property.

Several researchers have investigated the mechanical properties of natural fibre composite in hybrid woven form. Venkateshwaran and ElayaPerumal [13] studied the mechanical properties of banana-jute-epoxy hybrid composite by keeping woven banana mat and jute mats layer by layer and found that banana-jute-banana composite gives 
better properties than other combinations. Santulli et al [14] studied the mechanical properties of woven jute-woolepoxy composite and found that addition of wool fibre in woven jute-epoxy composite improves the mechanical properties of the composite. Jawaid et al [15] investigated the hybridization effect on mechanical properties for oil palm fruit bunches with woven jute composite and found that hybridized composite gives better tensile and flexural properties than individual-fibre-reinforced composite.

In order to improve the mechanical properties of the natural fibre polymer composite material, several researchers have suggested addition of glass fibre in the composite material. Ahmed and Vijayarangan [16] studied the mechanical properties of jute-glass-polyester composite and found that when glass fibre mat was kept as an outer layer, composite gives better mechanical properties. Harish et al [17] compared the mechanical properties of coir-epoxy and glass-epoxy composites and found that glass-epoxy composite gives better properties than coir-epoxy composite. However, coir fibres improve the mechanical properties of the hybrid composite. Ramesh et al [18] studied the effect of incorporation of glass fibre on mechanical properties for sisal and jute fibre composites. Their results showed that addition of glass fibre in the composites improves the mechanical properties of natural fibre composite. Thwe and Liao [19] compared the short bamboopolypropylene composite to bamboo-glass-polypropylene composite on mechanical properties such as tensile and flexural strength. Their results revealed that $20 \%$ by mass of glass fibre in the composite increases the tensile and flexural strength of bamboo composite by $7 \%$ and $25 \%$, respectively. Velmurugan and Manikandan [20] studied influence of weight percentage on mechanical properties of palmyra-glass sandwich composite by keeping the glass as skin and palmyra as core. They found that the sandwich effect increases the load carrying capacity of palmyra-glass composite.

Idicula et al [21] studied the dynamic mechanical properties of randomly oriented short banana-sisal hybrid composite and found that $40 \%$ volume fraction gives better properties. Tajvidi et al [22] compared the dynamic mechanical behaviour of various natural fibres such as kenaf, wood flour, rice hulls and newsprint fibres in polypropylene composites. They reported that kenaf fibre reinforcement increases the storage modulus of the composite than other fibre composites. Devi et al [23] studied influence of fibre volume percentage on the dynamic properties of pineapple leaf fibre-glass fibre-polyester composite and found that composite with $0.2 V_{\mathrm{f}}$ of glass fibre gives better storage modulus due to lower molecular mobility in the polymer chain. Tao et al [24] examined the dynamic mechanical properties of short ramie and jutepoly(lactic acid) composite and found that addition of natural fibre increases the dynamic properties. Jeyaraj et al [25] carried out a numerical investigation on the effect of thermal load on damping behaviour of laminated composite plate and found that the modal damping increases with temperature.
Most of the researchers investigated the hybrid composite by keeping natural fibre and glass fibres layer by layer or by intimately mixing the short glass and natural fibres. The present work analyses a novel intra-ply woven reinforcement of glass and natural fibres in mat form. A basket-type woven single mat consists of glass yarn in one direction and natural fibre yarn (banana or jute) in another direction of the mat. Effects of orienting glass and natural fibre yarns in the two different directions of the woven mat on the mechanical and dynamic mechanical behaviours have been investigated.

\section{Experimental details}

\subsection{Fibre mat and polymer preparation}

In the present work, glass fibre is chosen as a synthetic fibre while banana and jute fibres are chosen as natural fibres for the detailed study on synthetic-natural fibre intra-ply woven composite. Initially 100-140 loose natural and synthetic fibres are spurned into yarn separately. Later, a basket-type intra-ply woven fabric has been prepared using a hand-loom. From the previous study carried out by authors, it is found that basket-type woven fabric reinforcement gives better mechanical properties compared with twill, stain, plain and huckaback woven fabric reinforced composites [26]. Hence, in the present study, baskettype woven fabric is used to prepare different kinds of intraply woven composites. Figure 1 shows a schematic
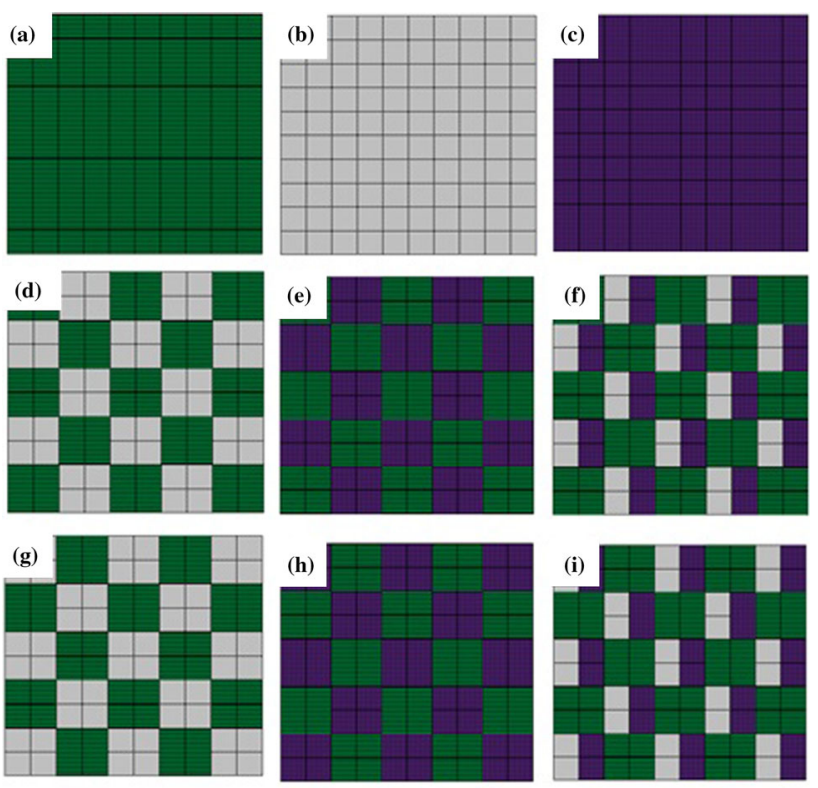

=Glass fibre

=Jute fibre

=Banana fibre

Figure 1. Schematic diagram of glass-natural fibre intra-ply mat. (a) WAWG, (b) WAWJ, (c) WAWB, (d) WGWJ, (e) WGWB, (f) WGWJAB, (g) WJWG, (h) WBWG and (i) WJABWG. 


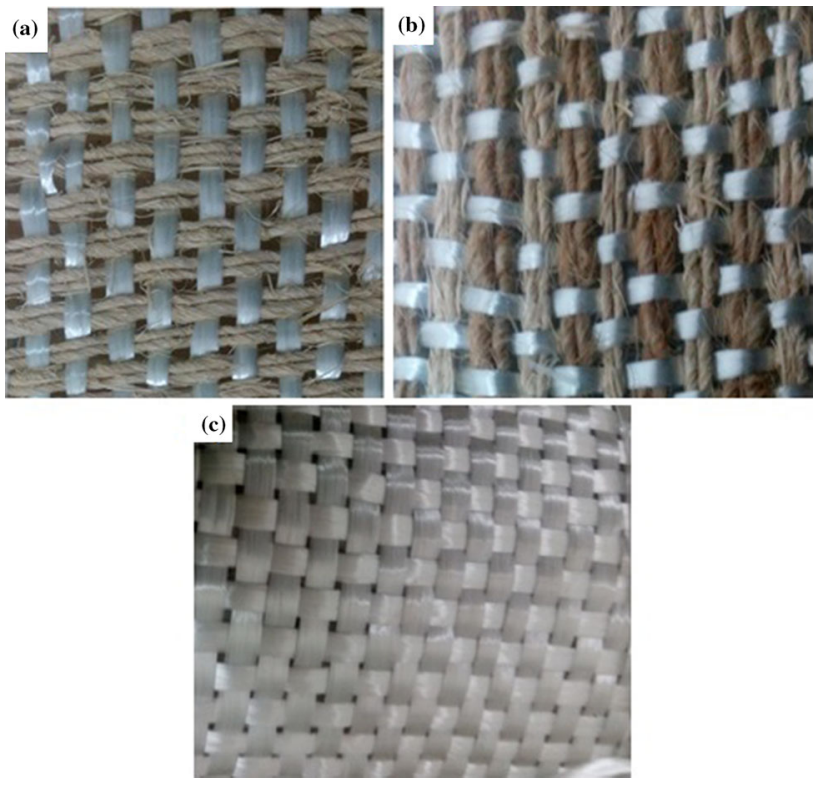

Figure 2. Different types of banana-jute-glass intra-ply woven mat. (a) WGWB, (b) WJWG and (c) WAWG.

diagram of different types of woven intra-ply hybrid glassnatural fibre mats used in the present work.

In this work, $1 \mathrm{wt} \%$ methyl ethyl ketone peroxide (MEKP) and cobalt naphthenate are used as a catalyst and accelerator, respectively, and mixed with the unsaturated isophthalic polyester in the ratio of 100:1:1. Different types of intra-ply woven fabric investigated in the present work are shown in figure 2. In order to analyse the effect of intra-ply woven hybridization of synthetic and natural fibres, individual natural fibres and synthetic fibres woven fabric reinforced composites were also investigated. Different types of hybrid intra-ply woven fabric are WAWG-glass in both warp and weft, WAWJ — jute in both warp and weft, WAWB — banana in both warp and weft, WGWJ-glass in warp and jute in weft, WGWB-glass in warp and banana in weft, WGWJAB - glass in warp and both banana and jute in weft, WJWG - jute in warp and glass in weft, WBWG-banana in warp and glass in weft and WJABWG_-both banana and jute in warp and glass in weft, as shown in table 1 .

\subsection{Fabrication of composites}

Different types of intra-ply woven fabric reinforced composite laminates investigated in the present work are prepared using a hand lay-up method. A silicon rubber mould of size $270 \mathrm{~mm} \times 250 \mathrm{~mm} \times 3 \mathrm{~mm}$ covered with stiff parallel granite plates is used. Initially a known amount of unsaturated isophthalic polyester resin, catalyst (MEKP) and accelerator (cobalt naphthenate) mixture is poured into the mould cavity; later the intra-ply woven hybrid fabric is placed over the resin mixture. Following this, the remaining resin mixture is poured again over the woven fabric with the help of a roller made of aluminium. It removes the voids
Table 1. Representation of different combinations of woven hybrid intra-ply composite.

\begin{tabular}{lcc}
\hline $\begin{array}{l}\text { S1. } \\
\text { no. }\end{array}$ & Type of fibre and weaving style & $\begin{array}{c}\text { Symbols used in the } \\
\text { report }\end{array}$ \\
\hline 1 & Both warp and weft glass fibre & WAWG \\
2 & Both warp and weft jute fibre & WAWJ \\
3 & Both warp and weft banana fibre & WAWB \\
4 & Warp glass fibre and weft jute fibre & WGWJ \\
5 & Warp glass fibre and weft banana \\
fibre & WGWB \\
6 & Warp glass fibre, weft jute and & WGWJAB \\
7 & Wanana fibre & WJWG \\
8 & Warp banana fibre and weft glass \\
fibre & WBWG \\
9 & Warp jute and banana fibre, weft & WJABWG \\
& $\quad$ glass fibre & \\
\hline
\end{tabular}

present in laminates. Finally, the mould is covered by a stiff parallel plate and a dead weight of $60 \mathrm{~kg}$ is placed over the plate to compress the laminates for $5 \mathrm{~h}$ under ambient temperature curing. Later the laminate is sized into several pieces according to the ASTM standard requirement for specimen of different mechanical tests and dynamic mechanical analysis.

\subsection{Testing standards}

2.3a Mechanical test: Three different mechanical properties of the intra-ply woven fabric composites analysed in the present work are tensile, flexural and impact strengths. Tensile test is conducted according to the ASTM D-638 standard while the flexural (three-point bending test) is conducted according to the ASTM D-790 standard on a universal testing machine. Impact strengths of the composites (without notch) are obtained from the izod impact test based on the ASTM D-256 standard. Apart from this, tensile test is conducted separately on different woven fabrics based on ASTM D-5034 standards.

2.3b Dynamic mechanical analysis: Storage modulus, loss modulus and material loss factor of the intra-ply woven fabric composite are calculated as a function of temperature using a dynamic mechanical analyser. The dynamic mechanical analysis test is conducted in nitrogen environment over a temperature range of $0-200^{\circ} \mathrm{C}$ at $1 \mathrm{~Hz}$ frequency.

\section{Results and discussion}

\subsection{Tensile properties of woven fabric}

Tensile characteristics of different intra-ply woven fabric are given in table 2. From table 2, it is clear that individual glass fibre woven fabric has better tensile properties, as anticipated. Similarly, individual natural fibre woven fabrics also have better tensile strength compared with glass-natural fibre intra- 
Table 2. Tensile properties of different types of woven natural fibre-glass fibre mat.

\begin{tabular}{lcc}
\hline Type & Tensile strength (MPa) & Tensile modulus (MPa) \\
\hline WAWG & 15.6 & 157 \\
WAWJ & 13.8 & 128 \\
WAWB & 6.45 & 55 \\
WGWJ & 2.78 & 83 \\
WGWB & 6.31 & 116 \\
WGWJAB & 3.28 & 92 \\
WJWG & 3.25 & 105 \\
WBWG & 3.81 & 42 \\
WJABWG & 2.39 & 40 \\
\hline
\end{tabular}

ply woven fabrics as seen in table 2 . Among the glass-natural fibre intra-ply hybrid woven fabrics, fabric with glass yarns in warp direction and banana fibre yarns in weft direction has better tensile properties compared with other types of intra-ply woven hybrid fabrics. This is attributed to the fact that strong glass fibre in warp direction and relatively weak banana natural fibre along the weft direction enhance the properties.

From table 2, it is observed that variation of tensile strength and modulus of woven fabric is not uniform. This is due to the tightness of yarn in warp and weft directions and it influences the strength and modulus. Individual woven fabric (glass, jute and banana) shows better strength and modulus, which vary uniformly according to strength of the fibre. This is due to weaving tightness in warp and weft directions. Same fibre in the warp and weft directions increases the tightness while glass-natural fibre reduces the tightness due to slippage. This increases the deformation at break. Hence it reduces the strength and modulus of woven fabric.

\subsection{Mechanical properties of intra-ply woven composite}

Tensile, flexural properties and impact strength of different intra-ply woven fabric reinforced composites are given in table 3. Due to the higher strength associated with the glass fibre, individual glass fibre woven fabric reinforced composite (WAWG) has better mechanical properties compared with individual natural fibre fabric reinforced composites and intra-ply woven glass-natural fibre hybrid fabric-reinforced composites. From table 3, it is clear that type of yarn in the warp and weft directions influences different mechanical properties of the intra-ply woven fabric reinforced composite in different ways.

Tensile properties of the intra-ply woven hybrid fabrics reinforced composite with glass fibre yarns in warp direction are better compared with the intra-ply woven hybrid composites with glass fibre yarns oriented along weft direction. This happens due to the higher strength glass fibre oriented along the tensile loading direction. Among the intra-ply woven hybrid fabric composites, WGWB composite has better tensile properties compared with other types of intra-ply woven hybrid composites. Even though jute fibre is relatively stronger than the banana fibre, tensile properties of the WGWJ composite are not better than WGWB composite. In both WGWJ and WGWB, glass fibre yarns are oriented along the warp direction, which is the tensile loading direction. The relatively strong jute yarns do not allow the glass fibre yarns to take more load. However, as the banana yarns are relatively weak, it allows glass fibre to take more load; hence, WGWB has better tensile behaviour compared with WGWJ. A similar observation has been reported by Rajesh and Pitchaimani [26] in their work on dynamic mechanical behaviour of jute-banana intra-ply fabric composite. They also found that relatively strong jute fibre in the warp direction and relatively weak banana fibre in the weft direction enhances the dynamic mechanical behaviour of the composite. This is due to less resistance provide by weak banana fibre against load carrying by stronger fibre in the warp direction.

Stress-strain curves of different types of composites analysed in the present work are given in figure 3. From figure 3 , one can observe that composites with glass fibre oriented along warp direction have better modulus. It is also observed that WGWB has high modulus. This can be attributed to less resistance provided by banana fibre

Table 3. Mechanical properties of hybrid woven natural fibre-glass fibre intra-ply composite.

\begin{tabular}{|c|c|c|c|c|c|}
\hline \multirow[b]{2}{*}{ Type } & \multicolumn{2}{|c|}{ Tensile properties } & \multicolumn{2}{|c|}{ Flexural properties } & \multirow{2}{*}{$\frac{\text { Impact properties }}{\text { Impact strength }}$} \\
\hline & $\begin{array}{c}\text { Tensile strength } \\
(\mathrm{MPa})\end{array}$ & $\begin{array}{l}\text { Tensile modulus } \\
\qquad(\mathrm{GPa})\end{array}$ & $\begin{array}{l}\text { Flexural strength } \\
(\mathrm{MPa})\end{array}$ & $\begin{array}{l}\text { Flexural modulus } \\
\qquad(\mathrm{GPa})\end{array}$ & \\
\hline WAWG & 90.0 & 0.897 & 69.1 & 2.505 & 992 \\
\hline WAWJ & 29.2 & 1.500 & 52.0 & 2.755 & 142 \\
\hline WAWB & 13.4 & 0.857 & 31.7 & 1.465 & 62 \\
\hline WGWJ & 26.3 & 0.931 & 49.0 & 1.920 & 752 \\
\hline WGWB & 31.0 & 1.290 & 30.0 & 1.275 & 326 \\
\hline WGWJAB & 25.4 & 0.604 & 15.6 & 1.215 & 500 \\
\hline WJWG & 17.9 & 0.946 & 39.6 & 1.715 & 173 \\
\hline WBWG & 9.84 & 0.935 & 38.9 & 1.600 & 57 \\
\hline WJABWG & 10.6 & 0.673 & 25.6 & 1.500 & 83 \\
\hline
\end{tabular}




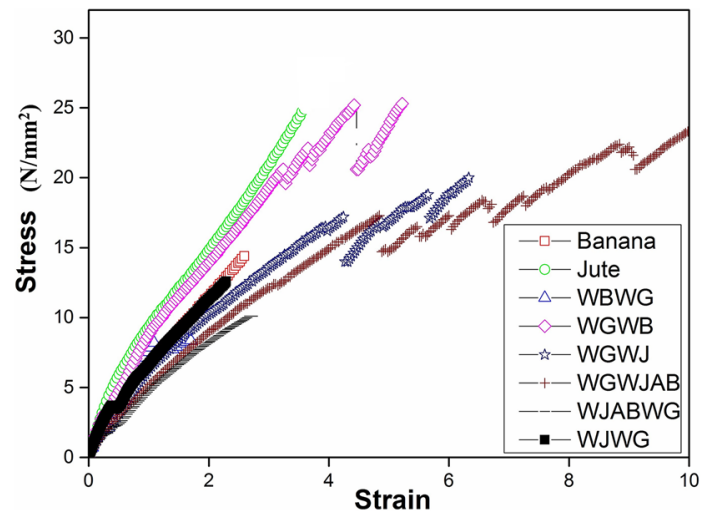

Figure 3. Stress vs strain from tensile test.

against higher load carrying capacity of glass fibre. These results indicate that the intra-ply hybridization of glass and natural fibre enhances tensile properties of the composite. This is also evident from poor brittle failure behaviour of banana fabric and jute fabric composites.

Surface morphology studies are carried out on the tensile fractured specimens using scanning electron microscope images to understand the load transfer mechanism between the fibres along warp and weft direction and between the fabric and matrix during loading. Figure $4 \mathrm{a}$ shows the tensile fractured surface of woven jute fibre composite. It reveals that the failure occurs in the warp direction due to tensile loading and indicates the uniform stress distribution in the loading direction. Figure $4 \mathrm{~b}$ and $\mathrm{c}$ shows the fractured surface of WBWG woven intra-ply hybrid composite under tensile load with different magnifications. It reveals that addition of glass fibre in the natural fibre composite damages the matrix material due to non-uniform stress distribution of fibre. This indicates that extremely strong glass fibre in the matrix carries higher load compared with banana natural fibre. Due to these drastic differences in the strength, banana fibre fails earlier and also damages the matrix.

Figure $4 \mathrm{~d}$ shows the failure of banana fibre surface in the WBWG composite. It indicates that banana natural fibre failure has brittle nature since it shows poor load carrying capacity compared with glass fibre. This causes severe damage in the matrix material, which is evident from figure 4c. A similar observation was noticed for WGWJ composite also. Figure 5c shows when glass fibre is oriented along warp or loading direction, it tries to carry more load. At the same time, natural fibres in the weft direction start to fail and cause severe damages in the matrix. Figure $5 \mathrm{c}$ reveals glass fibre damages in the matrix material near the fibre surface, which then propagate to the outer surface.

However, a similar kind of variation of flexural properties with the type of intra-ply hybrid woven fabric composites is not observed, as seen in table 3. Flexural properties of WGWJAB and WJABWG composites are poor compared with other intra-ply woven hybrid composites due to the presence of both natural fibres in the
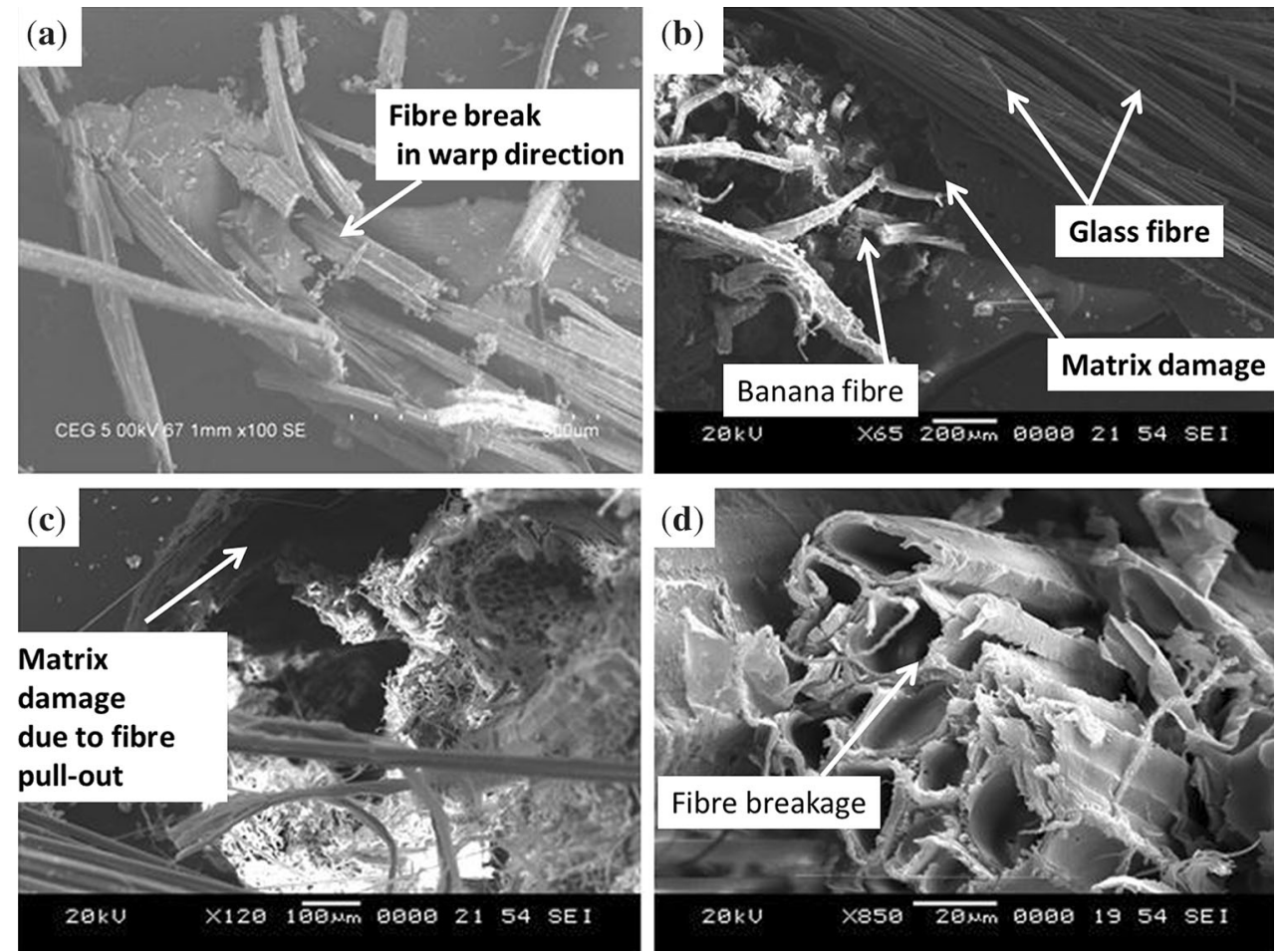

Figure 4. Micro-structure of woven composites. (a) Jute composite under tensile load. (b)-(d) WBWG composite under tensile load. 

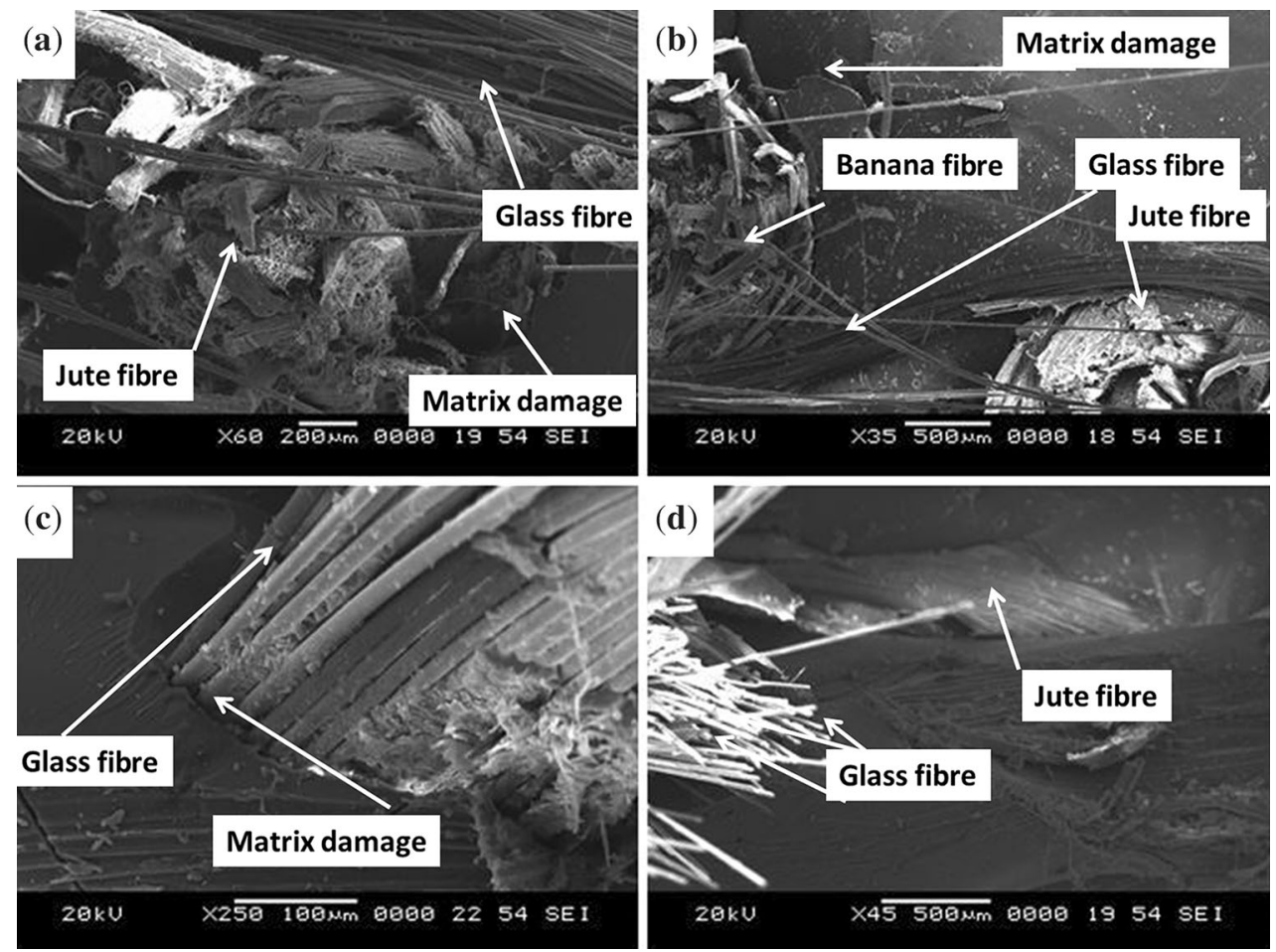

Figure 5. Micro-structure of woven composites. (a) WJWG composite under flexural load, (b) WJABWG composite under flexural load, (c) WGWJ under tensile load and (d) WGWJ under flexural load.

fabric along with glass fibre. This can be attributed to the poor stress transfer between the natural fibres when both the fibre yarns are present in the fabric along with the glass fibres. Results also revealed that for WJWG and WBWG the tensile properties of the intra-ply woven hybrid fabric composites do not vary significantly while WGWJ and WGWB composites tensile properties vary significantly. This is due to higher resistance offered by the jute yarns compared with banana yarns during the bending loading. The result indicates that for better tensile properties of intra-ply woven hybrid composites, relatively weaker natural fibre should be oriented along the weft direction of the fabric. Similarly, for better flexural properties, relatively stronger natural fibre should be oriented along the weft direction of the fabric.

Figure 5a shows the fracture surface of WJWG composite under flexural load. This reveals that WJWG composite under flexural load fails due to fibre pull-out; due to poor strength of fibre it could not carry more load. Hence, the composite fails either by fibre breakage or fibre pull-out and causes severe damages in the matrix material of composite. Similar observations can be made for WJABWG composite also. Figure 5b shows the presence of glass fibre and natural fibre (banana and jute) in the polyester composite. It also reveals that damage occurs in the matrix material due to non-uniform stress formation during composite loading under flexural load due to different fibre strengths. Figure 5d shows WGWJ composites fracture surface under flexural load. It reveals less damage on matrix material. This is due to the presence of jute fibre in weft direction. Even though jute fibre strength is not equal to that of glass fibre, compared with banana fibre, jute fibre has better strength. This jute fibre tries to transfer load uniformly but is drastically different compared with glass fibre composite at failure. However, it gives better stress transfer compared with glass-banana and glass-bananajute combination.

Similar to the tensile properties, the impact strength of the intra-ply woven hybrid fabric reinforced composite is better when the glass fibre is oriented along the warp direction and the impact strength is poor when the glass fibre is oriented along weft direction, as seen in table 3 . One can observe from table 3 that intra-ply hybridization of natural fibre with glass fibre increases impact strength of the composite significantly compared with tensile and flexural behaviour of the composite. The intra-ply hybridization of glass and natural fibre does not enhance the tensile and flexural strength of the composite. Individual jute fibre woven fabric reinforced (WAWJ) composite has better flexural and tensile strength. However, the impact strength of the glass-natural fibre intra-ply woven hybrid composites is several times higher than the individual natural fibre woven fabric reinforced composites. It is also observed that WGWJ composites impact strength is about $75 \%$ of the individual glass fibre woven composite (WAWG). From table 3, it is clear that impact strength of the intra-ply woven hybrid composite is better when the glass fibre is oriented along the warp direction. The reason 
for this is that glass fibre has a higher modulus than that of natural fibre, which increases the resistance against deformation. Glass fibre has higher stiffness, strength and toughness together in a single material than those of natural fibre. Hence, glass fibre can absorb more energy compared with natural fibre. Also glass fibre has higher aspect ratio compared with natural fibre; it offers better energy transfer between polymer and fibre upon load impact, and dissipates those impact forces throughout the composite instead of localizing them into one point. Also it provides resistance against cracking and rapid propagation throughout the specimen.

\subsection{Dynamic mechanical analysis}

Dynamic mechanical analysis studies carried out on different intra-ply woven fabric reinforced composites to investigate dynamic mechanical characteristics such as storage, loss modulus and material loss factor are presented in this section.

3.3a Storage modulus: Influence of type of woven fabric reinforcement on storage modulus of the composite as a function of temperature is shown in figure 6. Figure 6 reveals that individual jute fibre woven fabric reinforced composite has better storage modulus in both the glassy and rubbery region compared with the other types of composites. However individual glass fibre woven fabric reinforced composite has storage modulus higher than that of individual jute fibre woven composite in the glassy region, up to $70^{\circ} \mathrm{C}$. Beyond $70^{\circ} \mathrm{C}$ sudden drops in storage value occur for the individual glass fibre composite, and it has storage modulus value lesser than that of the jute fibre woven composite for higher values of temperature. This indicates that individual glass fibre woven composite loses its stiffness in the rubbery region due to the higher amount of molecular movement at temperature beyond $70^{\circ} \mathrm{C}$. Along with this, another reason for the behaviour of glass fibre composite is its typical brittle nature. Due to this brittle nature of glass fibre, intra-ply hybridization of glass and

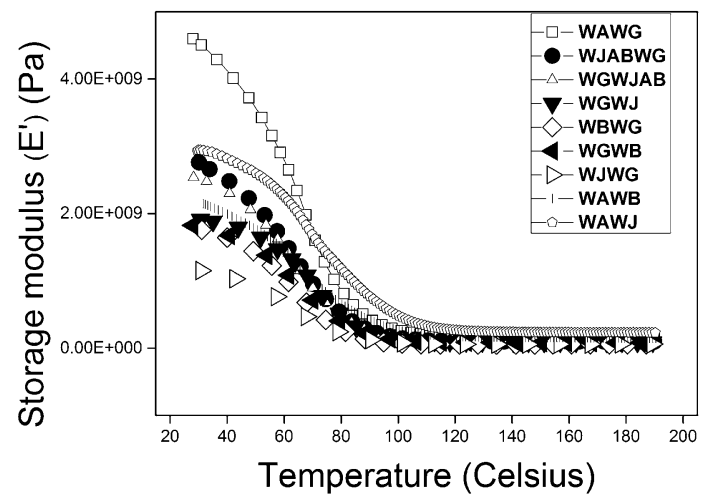

Figure 6. Effect of intra-ply hybridization with temperature on storage modulus. natural fibre does not enhance the storage modulus of the composite and results in storage modulus lower than that of individual jute fibre woven composite as seen in figure 6 . Figure 6 also reveals that intra-ply woven fabrics with glass fibre oriented along warp direction do not enhance the storage modulus of the composite.

3.3b Loss modulus: Influence of type of intra-ply woven fabric reinforcement on loss modulus of the composite as a function of temperature is shown in figure 7. From figure 7 , it is clear that variation of loss modulus of the individual glass fibre woven fabric composite with temperature is similar to the storage modulus variation. The width associated with WAWJ and WAWB fabric (individual natural fibre woven fabric) composite is larger than that of the WAWG and other intra-ply woven hybrid fabric composites as seen in figure 7 . This indicates better energy dissipation capability of individual natural fibre woven fabric composite compared with the other composites. Glass transition temperature of these WAWJ and WAWB composites is also higher than that of the other intra-ply woven composites. This can be attributed to the effective fibre matrix adhesion, which increases the frictional resistance for the molecular movement. Due to the brittle nature of glass fibre, the intra-ply woven hybrid fabric composites do not have a better glass transition temperature.

3.3c Material loss factor or tan $\delta$ : Influence of type of intra-ply woven fabric reinforcement on material loss factor of the composite as a function of temperature is shown in figure 8. Figure 8 also reveals that due to the higher molecular movement, the intra-ply woven glass-natural fibre hybrid composite has better material loss factor values than those of the natural fibre woven (WAWJ and WAWB) composites. From figure 8, it is observed that the peaks of WAWJ and WAWB composites shift towards the higher temperature side compared with glass-natural fibre intraply hybrid composite. This is due to lower molecular mobility of polymer chain in the presence of individual woven fabric. In the case of glass-natural fibre, tightness

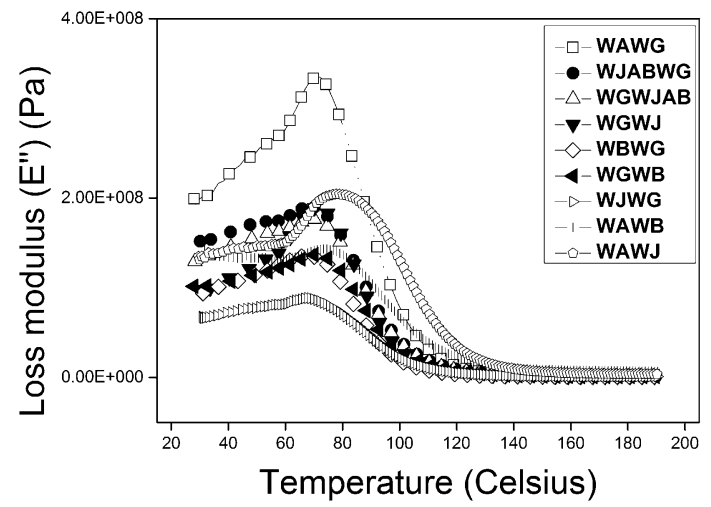

Figure 7. Effect of intra-ply hybridization with temperature on loss modulus. 


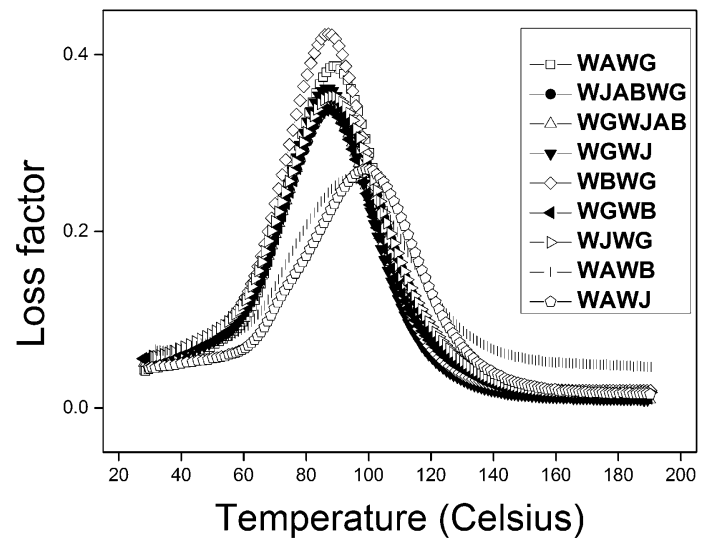

Figure 8. Effect of intra-ply hybridization with temperature on loss factor.

Table 4. Peak height and glass transition temperature of different composites.

\begin{tabular}{lccc}
\hline & & \multicolumn{2}{c}{ Temperature $\left({ }^{\circ} \mathrm{C}\right)$} \\
\cline { 3 - 4 } $\begin{array}{l}\text { Type of } \\
\text { composite }\end{array}$ & $\begin{array}{c}\text { Peak height of } \\
\tan \delta\end{array}$ & $\begin{array}{c}T_{\mathrm{g}} \text { from } \\
\tan \delta\end{array}$ & $\begin{array}{c}T_{\mathrm{g}} \text { from loss } \\
\text { modulus }\end{array}$ \\
\hline WAWG & 0.3870 & 89.9 & 70.9 \\
WAWJ & 0.2703 & 99.2 & 77.7 \\
WAWB & 0.2601 & 94.8 & 74.5 \\
WJWG & 0.3528 & 88.1 & 68.8 \\
WGWJ & 0.3617 & 87.4 & 71.3 \\
WBWG & 0.4232 & 87.1 & 67.9 \\
WGWB & 0.3383 & 87.1 & 71.1 \\
WJABWG & 0.3470 & 89.4 & 68.0 \\
WGWJAB & 0.3401 & 87.0 & 68.9 \\
\hline
\end{tabular}

between two different fibres such as glass and banana, jute natural fibre is poor compared with individual jute and banana fibre fabric. This would be the influence of interfaces of fibre and matrix. In the case of glass-natural fibre intra-ply fabric composite, peak height is higher compared with individual jute and banana fibre fabric composite. This reveals that glass-natural fibre fabric increases the interaction between fibre-fibre and fibre-matrix, which increases the energy dissipation of composite material. This is reflected in the peak height of the $\tan \delta$ value given in table 4 also.

3.3d Cole-Cole plot: Figure 9 shows the Cole-Cole plot of intra-ply hybrid glass-natural fibre composite. The plot indicates the structural behaviour of the matrix such as fibre-matrix interaction and homogeneity of the material due to incorporation of fibres in the matrix. From the results, it is found that addition of glass and natural fibre in the polymer matrix changes the material behaviour from homogeneity to heterogeneity, which is evident from the Cole-Cole plot. It shows that addition of glass and natural fibre in the polymer matrix changes the perfect semi-circle into imperfect semi-circular shape in Cole-Cole plot.

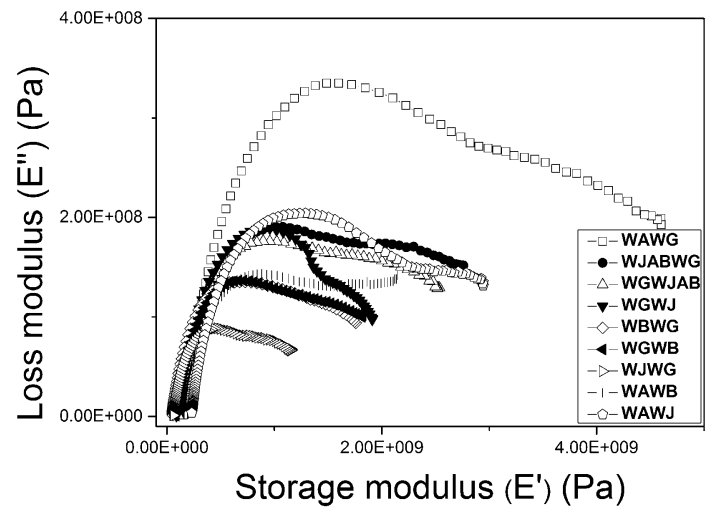

Figure 9. Cole-Cole plot of intra-ply hybrid woven composite.

\section{Conclusion}

Influence of orienting synthetic fibre yarns and natural fibre yarns in a basket-type woven fabric on mechanical and dynamic mechanical properties of a polyester composite has been investigated. It is found that intra-ply hybridization effect of synthetic and natural fibre yarns in a woven fabric is not significant on tensile and flexural characteristics of the composite. However, the intra-ply woven fabric hybridization enhances impact strength and damping characteristics significantly. It is observed that woven fabric composite with glass fibre yarns oriented along has better impact characteristics, while woven fabric composite with glass, jute and banana yarns shows better loss factor due to multi-level interaction between fibre-fibre in woven fabric and woven fabric-matrix.

\section{Acknowledgement}

Authors wish to thank Material Characterization Lab, Department of Mechanical Engineering, NITK, Surathkal, for the tensile and flexural tests.

\section{References}

[1] Venkateshwaran N, Elayaperumal A and Raj R A 2012 Mechanical and dynamic mechanical analysis of woven banana-epoxy composite. J. Polym. Environ. 20(2): 565-672

[2] Landel R F and Nielsen L E 1993 Mechanical properties of polymers and composites. Boca Raton: CRC Press

[3] Saheb D N and Jog J 1999 Natural fiber polymer composites: a review. Adv. Polym. Technol. 18(4): 351-363

[4] Fu S Y, Lauke B, Mder E, Yue C Y and Hu X 2000 Tensile properties of short-glass-fiber- and short-carbon-fiber-reinforced polypropylene composites. Compos. Part A: Appl. Sci. Manuf. 31(10): 1117-1125

[5] Lassila L, Nohrstrm T and Vallittu P 2002 The influence of short-term water storage on the flexural properties of unidirectional glass fiber-reinforced composites. Biomaterials 23(10): 2221-2229 
[6] Dweib M, Hu B, ODonnell A, Shenton H and Wool R 2004 All natural composite sandwich beams for structural applications. Compos. Struct. 63(2): 147-157

[7] Elbadry E A, Aly-Hassan M S and Hamada H 2012 Mechanical properties of natural jute fabric/jute mat fiber reinforced polymer matrix hybrid composites. Adv. Mech. Eng. 4: 354547

[8] Joshi S, Drzal L, Mohanty A and Arora S 2004 Are natural fiber composites environmentally superior to glass fiber reinforced composites? Compos. Part A: Appl. Sci. Manuf. 35(3): 371-376

[9] Corbire-Nicollier T, Laban B G, Lundquist L, Leterrier Y, Mnson J A and Jolliet O 2001 Life cycle assessment of biofibres replacing glass fibres as reinforcement in plastics. Resour. Conserv. Recycl. 33(4): 267-287

[10] Venkateshwaran N, Elayaperumal A, Alavudeen A and Thiruchitrambalam M 2011 Mechanical and water absorption behaviour of banana-sisal reinforced. Mater. Des. 32(7): 4017-4021

[11] Sastra H Y, Siregar J P, Sapuan S M and Hamdan M M 2006 Tensile properties of arenga pinnata fiber-reinforced epoxy composites. Polym. Plast. Technol. Eng. 45(1): 149-155

[12] Okubo K, Fujii T and Yamamoto Y 2004 Development of bamboo-based polymer composites and their mechanical properties. Compos. Part A: Appl. Sci. Manuf. 35(3): 377-383. doi:10.1016/j.compositesa.2003.09.017

[13] Venkateshwaran N and ElayaPerumal A 2012 Mechanical and water absorption properties of woven jute-banana hybrid composites. Fibers Polym. 13(7): 907-914

[14] Santulli C, Sarasini F, Tirillò J, Valente T, Valente M, Caruso A, et al 2013 Mechanical behaviour of jute clothwool felts hybrid laminates. Mater. Des. 50: 309-321

[15] Jawaid M, Khalil H A and Bakar A A 2011 Woven hybrid composites: tensile and flexural properties of oil palm-woven jute fibres based epoxy composites. Mater. Sci. Eng. A 528(15): 5190-5195

[16] Ahmed K S and Vijayarangan S 2008 Tensile, flexural and interlaminar shear properties of woven jute and jute-glass fabric reinforced polyester composites. J. Mater. Process. Technol. 207(13): 330-335

[17] Harish S, Michael D P, Bensely A, Lal D M and Rajadurai A 2009 Mechanical property evaluation of natural fiber coir composite. Mater. Charact. 60(1): 44-49

[18] Ramesh M, Palanikumar K and Reddy K H 2013 Mechanical property evaluation of sisal-jute-glass fiber reinforced polyester composites. Compos. Part B: Eng. 48: 1-9

[19] Thwe M M and Liao K 2002 Effects of environmental aging on the mechanical properties of bamboo-glass fiber reinforced polymer matrix hybrid composites. Compos. Part A: Appl. Sci. Manuf. 33(1): 43-52

[20] Velmurugan R and Manikandan V 2007 Mechanical properties of palmyra-glass fiber hybrid composites. Compos. Part A: Appl. Sci. Manuf. 38(10): 2216-2226

[21] Idicula M, Malhotra S, Joseph K and Thomas S 2005 Dynamic mechanical analysis of randomly oriented intimately mixed short banana-sisal hybrid fibre reinforced polyester composites. Compos. Sci. Technol. 65(78): 1077-1087

[22] Tajvidi M, Falk R H and Hermanson J C 2006 Effect of natural fibers on thermal and mechanical properties of natural fiber polypropylene composites studied by dynamic mechanical analysis. J. Appl. Polym. Sci. 101(6): 4341-4349

[23] Devi L U, Bhagawan S and Thomas S 2010 Dynamic mechanical analysis of pineapple leaf-glass hybrid fiber reinforced polyester composites. Polym. Compos. 31(6): 956-965

[24] Tao Y, Yan L and Jie R 2009 Preparation and properties of short natural fiber reinforced poly(lactic acid) composites. Trans. Nonferr. Met. Soc. China 19: s651-s655

[25] Jeyaraj P, Ganesan N and Padmanabhan C 2009 Vibration and acoustic response of a composite plate with inherent material damping in a thermal environment. J. Sound Vib. 320(1): 322-338

[26] Rajesh M and Pitchaimani J 2016 Dynamic mechanical analysis and free vibration behavior of intra-ply woven natural fiber hybrid polymer composite. J. Reinf. Plast. Compos. 35(3): $228-242$ 